\title{
BANDED INTRACOCHLEAR ELECTRODE ARRAY: EVALUATION OF INSERTION TRAUMA IN HUMAN TEMPORAL BONES
}

\author{
R. K. SHEPHERD, BSC, DED \\ B. C. PYMAN, FRACS
}

\author{
G. M. Clark, PhD, FRACS \\ R. L. WEBB, FRACS
}

East Mlibourne, AUsthalia

\begin{abstract}
A banded free-fit scala tympani array was inserted into the basal turn of nine human cochleas to evaluate the trauma produced by the procedure. These nine cochleas, together with five nonimplanted controls, were serially sectioned and examined microseopically for damage to the nembranous labyrinth, in particular the spiral ligament, the basilar and Rejssner's membranes, the stria vaseularis, and the osseous spiral lanina. The severity and location of any trauma along the cochlear spiral were recorded. The results indicate that the insertion of the banded scala tympani arrat resulted in mininal mechanical damage, occurring prinarily to a localized region of the spiral ligament. This would not result in significant neural degeneration, and therefore would not compromise the cfficacy of the multichannel cochlear prosthesis.
\end{abstract}

KEY WORDS - rochlear inplant, intracochlear electrode, tranma.

\section{INTRODUCTION}

A number of safety issues are associated with artificial electrical stimulation of the auditory nerve. First, insertion trauma should be minimal and not lead to degeneration of the auditory nerve. Second, long-term electrical stimulation must not be harmful to the residual nerve population. Third, the materials used must be biocompatible, and the metal electrode must not be susceptible to significant dissolution as a result of long-term stimulation. Fourth, the device and the implant surgery must be designed to minimize the chances of infection. This paper examines the trauna associated with the insertion of a free-fit scala tympani electrode array in human temporal bones; previous papers from this laboratory have examined the other safety issues outlined. ${ }^{i-1}$

Investigators have used a number of anatomical approaches to electrically stimulate the eighth nerve in order to provide auditory information for the profoundly and totally deaf. ${ }^{5-10}$ The most popular approach has been to introduce the eleetrode array along the scala tympani via the round window: this approach has also been supported by a number of animal studies. ${ }^{+11-1+}$ The scala tympani array developed by the University of Melbourne, Department of Otolaryngology, in association with Nueleus Limited (Lane Core, New South Wales, Australia) eonsists of 22 platinum band electrodes and a Silastic MDX-4 4210 carrier. The present study cvaluates the tramma associated with the insertion of this array. Human cadaver temporal bones were used, and the insertion technicpue followed the surgical protocol developed by this group. '

\section{METHODS AND MATERIALS}

Electrode Aray. Fach electrode array comsisted of 22 lo 28 palinum bands in a Silastic MDX-4-42I0 carrier (Fir I). The most apical 22 platinum bands each had an $0.025-1 \mathrm{~mm}$ Tefloninsulated platinum iridimon (90) 10 ) wire welded to it: the remain ine bands were adcled to improse the mechanical stifteness of the proximal section of the array and were mot losed as edectrodes. Fach platinum band was $0.3 \mathrm{~mm}$ wide and the interelectrode spacing was 0.15 mon. 'Iwe lypes of array dimenbions were ned. the stepped arrat and the tapered arras. The stepened arras had

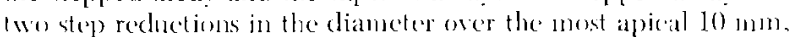
from $0.600 .5 \mathrm{~m}$ tom and $0.5(0) 0.4 \mathrm{~mm}$. The tapered arras had an even reduction in dianeter from an 0.6 to $0.4-m m$ tip. oser a 25-mm length. Beth artays were mamelactured asinge injection molding techuisues. onsiring a smonth array wille no irregularities between the chectrode bands and the carrier material.

Preparation of Temporal Bones. Fourteen temporal bones were used in this stucls. fise of which were controls. The temperal bones were obtained at pestnortem examination and were from

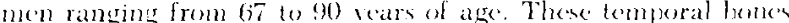
wore not frozen or fised prior to chectrode insertions. which was carried out within 21 houm of dealh.

Following the resection of the lemporal bone, the trmantio membrane " as ruptured and the roof of the midelle car operned. The bones were stored in normal saline at 4 " $C$ prior to electrode insertion. A brief modical history "as obtained and temperal bones from patients thomght to have suffered ofosclermis.

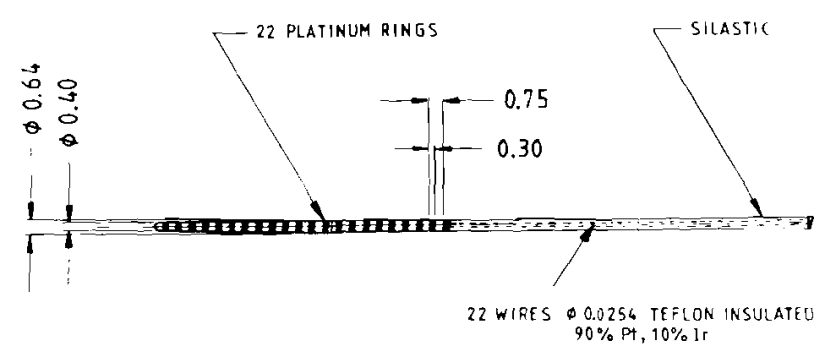

Fig 1. Diagram of tapered multiple-electrode array, (Reprinled with permission of Nucteus Linnited.)

From the Department of Otolarygology. University of Melbourne, The Royal Victorian Eye and Ear Hospital, East Melbourne, Australia. Supported by the Department of Seinee and lechnology of the Australian Commonwealth Government and Nucleus Limited.

REPRINTS-- R. K. Shepherd. Dept of Otolargngology, Unis of Melbourne, East Melbourne, Victoria 3002 , Australia. 

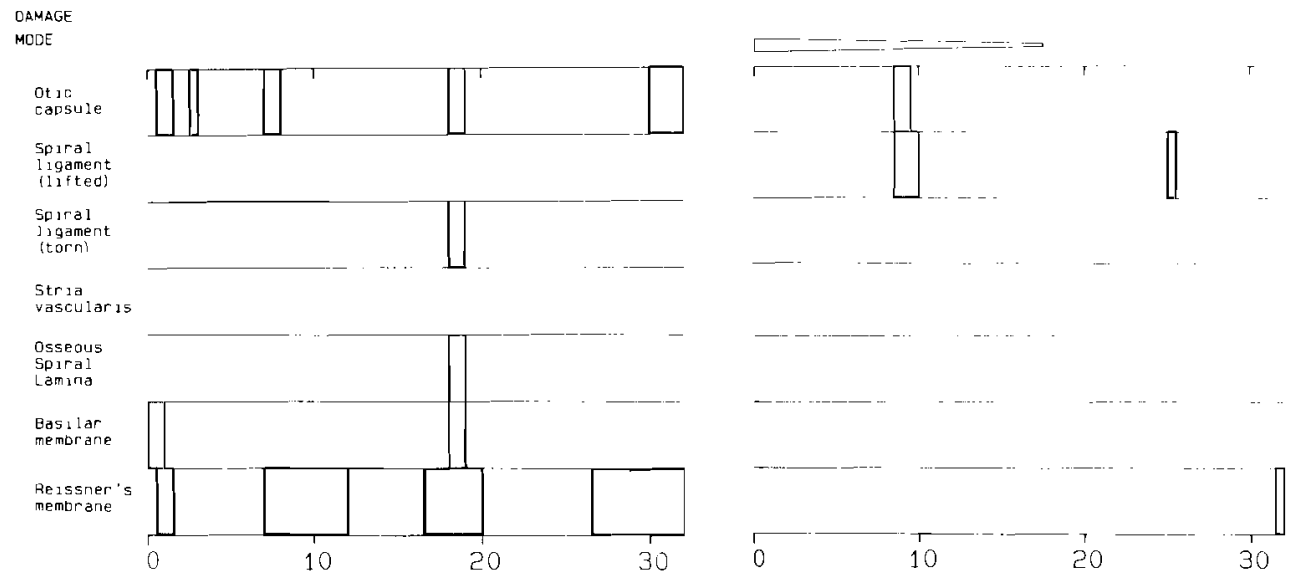

A

$\mathbf{B}$
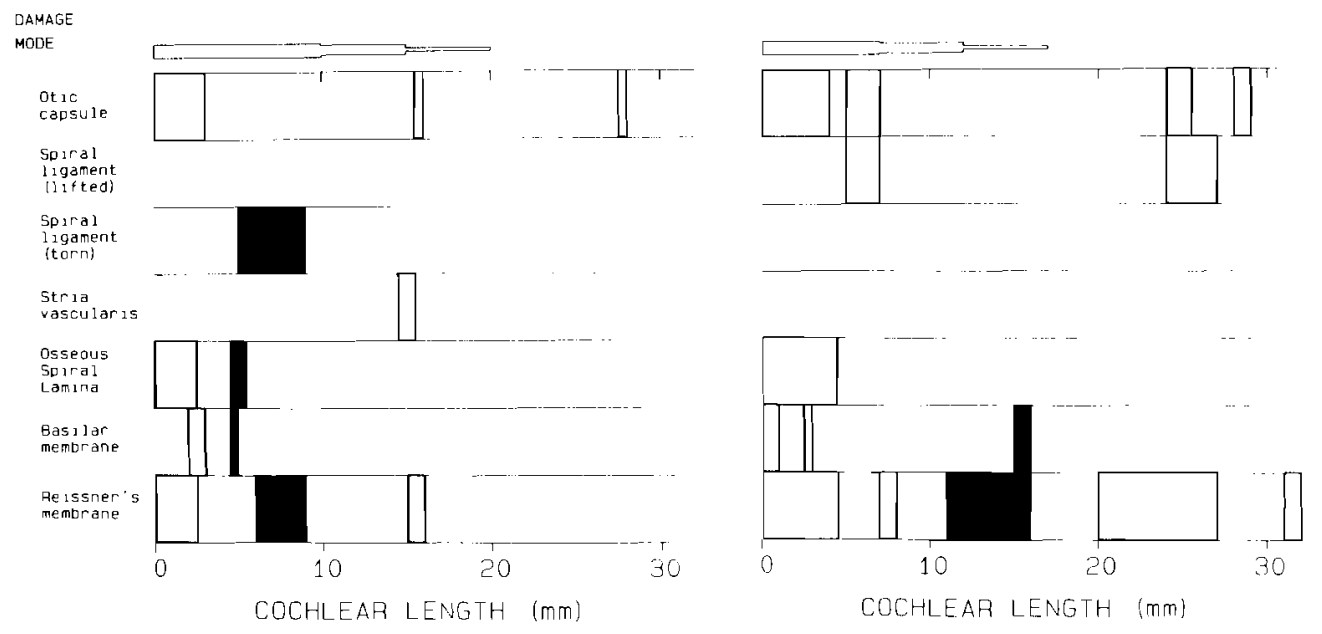

C

D

Fig 2. Temporal bone cochleograms. $\square-$ artifact, $\square$ - electrode insertion trauma. A) Control IS-8. Five small holes drilled into otic capsule resulted in widespread damage to Reissner's membrane and localized damage to basilar membrane and osseous spiral lamina. B) Bone IS-18. Tapered electrode array inserted with ease to $17.5 \mathrm{~mm}$ produced negligible damage as result of insertion. C) Bone IS-20. Stepped electrode array was inserted to $10 \mathrm{~mm}$ where resistance was felt. Array was withdrawn and reinserted to 17 $\mathrm{mm}$ with ease. Microclaw assisted further insertion to $20 \mathrm{~mm}$, and buckling in basal turn prevented further insertion. Insertion trauma included 4-mm tear along spiral ligament, 3-mm tear along Reissner's membrane, and 1-mm fracture of osseous spiral lamina. Associated with this fracture was $0.5-\mathrm{mm}$ tear of basitar membrane. Other damage was due to preparation artifact. D) Bone IS-15. Stepped electrode array was inserted with ease to $17 \mathrm{~mm}$, the point of first resistance. Damage as result of insertion was restricted to $1-\mathrm{mm}$ tear of basilar membrane, $15 \mathrm{~mm}$ from round window, and associated $5-\mathrm{mm}$ tear along Reissner's membrane. The perforation in basilar membrane was slightly larger than array tip diameter. Other damage was due to preparation artifact.

obliterative labyrinthitis, and tumors or fractures of the region were not included in the study. The temporal bones were prepared for cochleotony by a standard mastoidectomy and posterior tympanotomy. The preparation of the round window proceeded under magnification. The bone overhanging the round window was drilled away, and the round window membrane was exposed and incised using a fine hook. Care was taken to avoid damage to the osseous spiral lamina superomedially to the round window. If the cxposure of the basal turn was not adequate, the opening was enlarged anteroinferiorly using an 0.6-nm diamond paste drill. A record of the anatomical features of the round window and the basal turn of the scala tympani was made for each cochlea. The eleetrode array was then gently inserted using a microclaw designed for this procedure. 'A new array was used for cach temporal bone, and it was inserted to $25 \mathrm{~mm}$ or to a point where slight resistance was felt. No at tempt was made to force the electrode beyond the point of first resistance; however, in a number of cases the array was withdrawn and a second insertion attempted. Following each insertion, the array was gently withdrawn and the insertion distance measured using vernier calipers,
Each temporal bone was then prepared for histological examination: the stapes footplate was removed, the oral window opened, and the superior semicireular canal exposed. The temporal bones were placed in formal saline at $4^{\circ} \mathrm{C}$ for at least 48 hours, and then rinsed in distilled water. During the fixation schedule, each temporal bone was trinmed and the otic capsule thinned to within $1 \mathrm{~mm}$ of the membramous labyrinth using diamond paste drills. Openings wore made into the cochlea. and although this led to the production of a histologieal artifact. it was essential for adeçuate infiltration of the c'mbedding resin into the cochlea. The cochleas were decalcified in $14 \%$ EDTA in neutral buffered formalin and embedded in Spurr's resin. The blocked cochleas were sectioned at a thickness of $3 \mu \mathrm{m}$, and rections everv $1.30 \mu \mathrm{m}$ were collected and stained with hematoxylin and eosin.

Histological Examination. Graphic reconstruction of each enchlea was carried out using a technique deseribed by Sehuknecht . " This enabled the turns of each section to be located along the length of the eochlea. Damage to the osseous spiral lamina, basilar membrane, spiral liganent, stria vaseularis, and Reissner's membrane were recorded. In addition, damage to the 


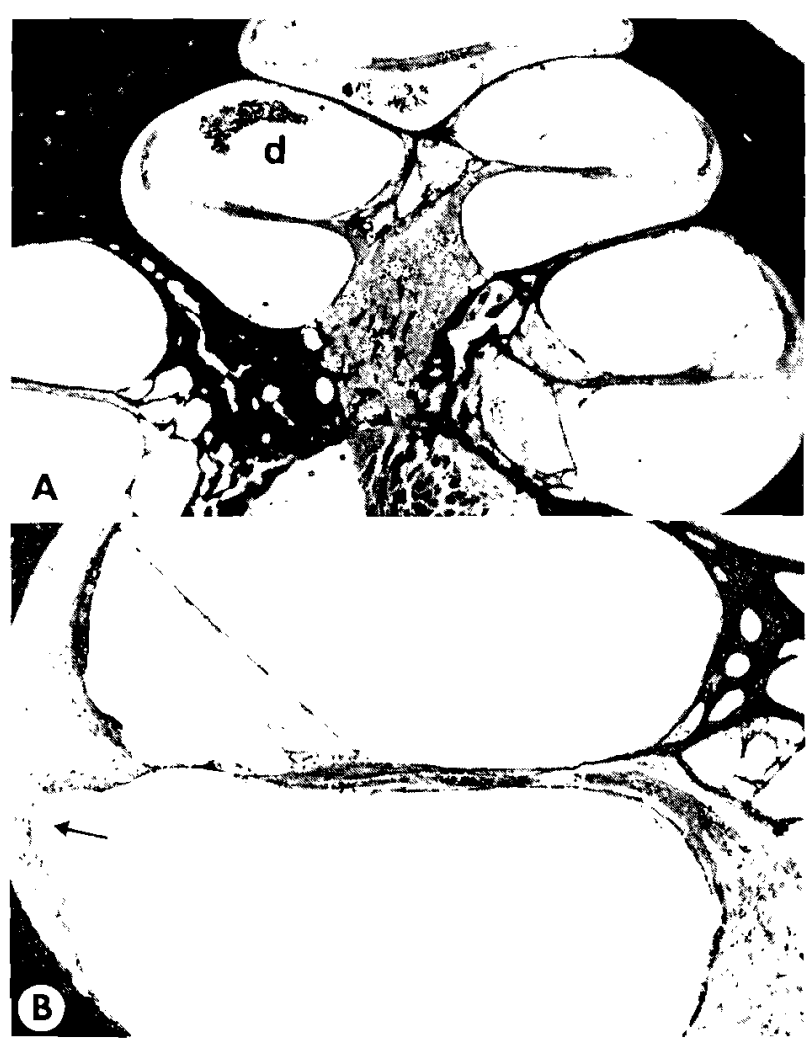

Fig 3. Cochlear photomicrographs. A) Bonc IS-18 (original $\mathrm{x} 23$ ). Tapered electrode array was inserted $17.5 \mathrm{~mm}$ without damage to membranous labyrinth. Bone dust (d) in middle and apical turns is preparation artifact. B) Bone IS-21, basal turn, approximately $10 \mathrm{~mm}$ from round window showing tear in spiral ligament of scala tympani (arrow) (original $\times 58$ ).

otic capsule during histological preparation and the resultant trauma to the membranous labyrintl were also noted. Cochleourams showing the tramma of different cochlear structures plotted along the length of the cochlea were constructed for implanted and control cochleas.

\section{RESULTS}

The electrode insertion distance for the nine cochleas varied from 15.5 to $27 \mathrm{~mm}$ with a mean insertion distance of $18.6 \mathrm{~mm}(\mathrm{SD}=3.5 \mathrm{~mm})$.

Examination of the five control cochleas revealed that drilling the otic capsule during the histological preparation was generally associated with damage to a number of structures within the scalae. Figure $2 \mathrm{~A}$ is an illustrative cochleogram showing the artifact produced as a result of drilling trauma. Lifting of the spiral ligament from the otic capsule adjacent to the site of drilling occurred in four bones and a tear of the spiral ligament was present in one bone. Tears along Reissner's membrane were frequently associated with this damage, and were up to $5 \mathrm{~mm}$ long. Occasionally, tears were observed in Reissner's membrane in regions remote from the site of drilling. Other cochlear structures damaged included the osseous spiral lamina and the basilar membrane. Both forms of damage were localized to the area of drilling, and were generally associated with severe damage to the otic capsule; they were observed in all five control temporal bones.

Trauma resulting from the insertion of an electrode array was examined in nine temporal bones. In three bones there was no evidence of any trauma to the cochlear structures that could be attributed to the electrode insertion (Figs $2 \mathrm{~B}$ and $3 \mathrm{~A}$ ). The most common injury was a tear in the spiral ligament which typically occurred 7 to $11 \mathrm{~mm}$ from the round window in five of the nine cochleas (Fig 2C). A photomicrograph of one of these tears is shown in Fig 3B. Three of these cochleas (IS-12, 20, and 21) had an associated tear in Reissner's membrane (Fig $2 \mathrm{C}$ ). In one of the nine cochleas (IS-15), it appeared that the tip of the electrode array penetrated the basilar and Reissner's membranes, coming to rest in the scala vestibuli (Fig 2D). The surgeon reported that the electrode array was inserted to a point where resistance was felt. Although the basilar membrane was torn, damage did not extend to the osseous spiral lamina. This was the only cochlea where the electrode array had deviated from the scala tympani and had penetrated the basilar membrane. In another cochlea (IS-21) there were two breaks in the basilar membrane totalling $3 \mathrm{~mm}$ in length, and these were associated with tears along the spiral ligament. Damage to the osseous spiral lamina as a result of electrode insertion was observed in one cochlea (IS-20), resulting in a $1-\mathrm{mm}$ fracture approximately $5 \mathrm{~mm}$ from the round window, and was associated with a tear of the basilar membrane (Fig 2C). This damage resulted from the array buckling in the basal turn.

Examination of the type and frequency of electrode insertion-induced trauma revealed no significant difference between the stepped and tapered electrode arrays.

\section{DISCUSSION}

The present study indicates that the insertion of the banded scala tympani array into the human cochlea results in minimal mechanical trauma to the membranous labyrinth. Damage to the osseous spiral lamina and basilar membrane - damage which would result in neural degeneration - was observed in three of the nine implanted cochleas, and was restricted to a few small locations along the cochlea. It was primarily due to attempts to force the electrode in farther after significant resistance had been felt, and could have been avoided by care in this respect.

The most common mode of cochlear trauma present was a tear along the spiral ligament in the scala tympani, typically between 7 and $11 \mathrm{~mm}$ from the round window. This is the region where the array would first come against the outer bony wall, following insertion through the round window. It is significant that the surgeons reported some difficulty introducing the arrays past the $10-\mathrm{mm}$ region in 
four of the five cochleas with these tears (IS-12, 13 , 17 , and 20 ). The histopathological consequences of this mode of trauma have not been thoroughly investigated. Johnsson et $\mathbf{a l}^{16}$ reported that the site of maximum spiral ligament damage in a patient who had received bilateral cochlear implants resulted in a very small fibrotic reaction. It is also possible that osteogenesis would be associated with the fibrosis, as new bone growth following damage to the endosteum has been reported in animal studies. ${ }^{17}$ However, tears in the spiral ligament without damage to the basilar membrane or osseous spiral lamina should not result in neural degeneration.

In contrast, local neural degeneration would have been expected following tears in the basilar membrane (IS-15 and 21), and the fracture of the osseous spiral lamina (IS-20). Both modes of trauma have been extensively investigated in animal studies, and the results have consistently demonstrated that such trauma will result in severe neural degeneration localized to the site of injury..$^{41-14}$ All investigators report subsequent new bone growth in the region associated with a fracture of the osseous spiral lamina; however, there is conflicting data available concerning the repair of the basilar membrane. Simmons" reported a periendolymphatic fistula after 9 months following trauma to the basilar membrane in a cat cochlea; however, Johnsson et al $^{16}$ reported considerable repair of both ruptured basilar and Reissner's membranes in both cochleas of a bilaterally implanted patient. The ability of a fistula to repair may restrict the area of neural degeneration.

In three cochleas (IS-12, 20, and 21), tears along the spiral ligament in the scala tympani were associated with tears of Reissner's membrane. There is limited and conflicting animal data available from which to draw the probable histopathological consequences of this trauma. In a study using guinea pigs, where damage was restricted to a perforation in Reissner's membrane, the membrane healed within 2 weeks and resulted in localized outer hair cell and occasional inner hair cell loss. ${ }^{18}$ On the other hand, in a study where electrode arrays were fed along the scala vestibuli following an apical ex- posure in cat cochleas, perforation of Reissner's membrane resulted in an $80 \%$ to $90 \%$ loss of spiral ganglion cells in an area localized to the site of trauma. ${ }^{12}$ Significantly, in this study the perforation of Reissner's membrane resulted in a permanent periendolymphatic fistula. Thus it is possible that the degree of local neural degeneration associated with trauma to Reissner's membrane depends on the ability of the membrane to heal, and is less likely if the electrode penetrates the membrane.

In the present study, the trauma associated with the insertion of the banded scala tympani array indicates that the array follows the outer bony wall of the scala tympani as it passes around the cochlea. Micrographs showing the location of other free-fit arrays within the scala tympani also support this observation. ${ }^{14.16}$ This finding indicates that the passage of the free-fit array is well away from the osseous spiral lamina, therefore reducing the chance of trauma to this structure. However, the array appears to pass close to the basilar membrane, thus making this membrane susceptible to tearing if the array deviates from its course along the scala tympani. In the single case where the basilar membrane was perforated by the array, the osseous spiral lamina was not damaged.

We attempted to maintain the mechanical properties of the cochlear membranes so that they would approximate the condition of the cochlea at surgery. It was felt that freezing or fixing the temporal bones prior to insertion could result in significant changes in the mechanical properties of the membranous labyrinth. ${ }^{19}$ In addition, the effect of postmortem autolysis was kept to a minimun by ensuring that the temporal bones were stored in cold normal saline, and by inserting the electrode arrays within 24 hours of death. There are a number of limitations of this study that should be noted. First, all the temporal bones were obtained from men, and thus are not representative of the size variations among the normal population. Second, the age of patients from which temporal bones were obtained may also effect the results, as there is evidence that the spiral ligament and basilar membrane change their structural characteristics in old age. ${ }^{19.20}$ ACKNOWLEDGMENTS - We thank Drs M. S. Kleid and D. W. Marty; J. F. Patrick, J. A. Kuzma, Dr M. S. Hirshorn, and G. B. Lavery of Nucleus
Limited; D. Bloom for the histology, and A. Brock for typing the manaseript.

\section{REFERENCES}

1. Black RC. Hannaker P. Dissolution of snooth platinum electrodes in biological fluids. Appl Neurophysiol 1979: 42 : $366-74$.

2. Clark GM. Pyman BC, Pavillard RE. A protocol for the prevention of infection in cochlcar implant surgers. I Laryngol Otol 1980: 94:1377-86.

3. Clark GM, Pyman BC. Webb RL, Bailey QE, Shepherd RK. Surgery for an inproved multiple-channel cochlear implant. Ann Otol Rhinol Laryngol 1984: 93:204-7.

4. Shepherd RK, Clark GM. Black RC. Chronic electrical stimulation of the auditory nerve in cats: physiological and histopathological results. Acta Otolaryngol (Stockh) 1984 (supp) 399) : 19-31.
5. Simmons FB. Electrical stimulation of the anditory norve in man. Areh Otolaryngol 1966: 84:24-73.

6. Michelson RP. Electrical stimulation of the human eochlaa: a proliminary report. Arch Otolaryngol 1971: 9:3:317-23.

7. House WF. Lrban J. Lometerm results of electrode inplantation and electrical stimulation of the eochlea in man. Ann ()tol Rhinol laryngol 1973; 82:504-10.

8. Clark GM. Hallworth RJ. A multiple-electrode array for a cochlear implant. J Laryngol Otol 1976:90:(623-7.

9. Pialoux P. Chouard CH. MacLood P. Physiological and clinical aspects of the rehabilitation of total deafness by implantation of multiple intracochlear electrodes. Acta Otolaryngol 
(Stockh) $1976: 81: 436-41$

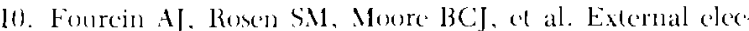

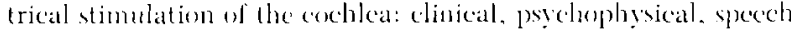
pereeptual and histological lindings. $13 \mathrm{r}$ J Audiol 1979) 1:3:85-107.

11. Simmons leb. Jermanent intracochlear clectrodes in cats.

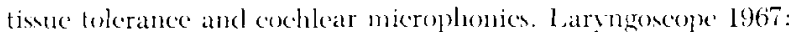
$77: 171-86$

12. Clark (X). An evalualion of per-sealar cochlear electrode implantation techniques - an histopatholonical study in cals. I Laryegol onol 197\%: $91: 185-999$

13. Schindler RA, Mergenieh MM. White MW, Bjockroth B Malticlectrode intracochlear inplants: nerve survial and stin-

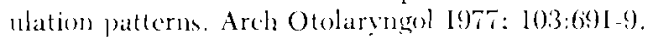

14. Sulton 1). Miller JM. l'lingst BE. Comparisoni of cochlear histopatholege lollowing (wo implant designs for nse in scala

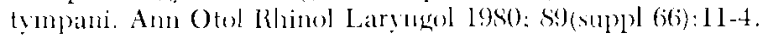

15. Schuknecht HF. Techniques for study of cochlear function and pathology in experimental animals. Arch Otolaryngol 1953: $58: 377-97$

16. Johnson l.C. Ilouse WF, Lintlicum FH. Otopathological findings in a patient with bilateral cochlear implants. Ann Otol Rhinol Laryngol 1982:91 (sup) pl 91):74-89.

17. Schindler laA. The cochlear histopathology of chronic in tracochlear implantation. J Laryngol Otol 1976:90:445-57.

18. Duvall AJ. Rhodes VT'. Ultrastructure of the organ of Corti following intermixing of cochlear [luids. Ann Otol Rhinol Larvingol 1967: 76:688-708.

19. Schuknecht HF l'athology of the ear, Cambridge, Mass: Larvard University l'ress. 1974:11, 388-98.

20. Schuknecht IfF. Further observations on the pathology of presprewis. Arch Otolaryngol 1964: 80:369-82. 


\section{University Library}

\section{- M M N E R VA A gateway to Melbourne's research publications}

Minerva Access is the Institutional Repository of The University of Melbourne

Author/s:

Shepherd, R. K.;Clark, Graeme M.;Pyman, B. C.;Webb, R. L.

Title:

Banded intracochlear electrode array: evaluation of insertion trauma in human temporal bones

Date:

1985

Citation:

Shepherd, R. K., Clark, G. M., Pyman, B. C., \& Webb, R. L. (1985). Banded intracochlear electrode array: evaluation of insertion trauma in human temporal bones. Annals of Otology, Rhinology and Laryngology, 94(1), 55-59.

Persistent Link:

http://hdl.handle.net/11343/27220 